\title{
Ocean Sciences Education for the 21st Century
}

\author{
Sharon H. Walker \\ The University of Southern Mississippi - Ocon Springs, Mississippi USA \\ Paulla Coble \\ Lniversity of South Florida - St. Petersburg, Florida LISA \\ Frances Lee Larkin \\ College of Williom and Mary $\bullet$ Gloucester Point, Virginin USA
}

\section{Introduction}

Never before has the need for science literacy within our citizenry been more critical than it is today. New technologies, increased environmental stresses with global implications, precollege teacher shortages, and the need for additional students majoring in math, science, and engineering require responsible decisionmaking at all levels of government. Yet despite ongoing efforts at math and science reform, two landmark studies, A Nation At Risk (U.S. National Commission on Excellence, 1983) and Educating Antericans for the 21st Contury (U.S. National Science Board, 1983), followed more recently by reports from two equally powerful efforts-the National Scince Foundation Survey Report (1988) and the Third International Math and Science Study [TIMSS] (National Scionce Tenchers Associotion [NSTAT Reports, 1996)-have re-enforced our awareness of the lack of competitiveness exhibited by this country's public schools and its students in math and science when compared to other countries. Major problem areas are inadequate $\mathrm{K}-12$ science and math curricula, which are "a mile wide and an inch deep" (NSTA Reports, 1996), inadequate teacher preparation, and lack of continuing education opportunities for inservice teachers. Science education literature is replete with research over the last two decades that concludes science teaching and learning need to be improved nationally. And, the authors of this manuscript believe that as we enter this new millennium, there remains a pronounced disconnect between scientists' research results and bridging the gap between the interpretations and relevance of those data to teachers, precollege students, and the general public. The disconnect and the subsequent need for enhanced ocean sciences education is clearly recognized by members of the oceanographic community, from scientists to classroom and informal education experts (Consortium for Oceanographic Research and Education, 1996).
According to the NSTA (2000), the nation's 52 million students are taught by 186,000 secondary and middle school science teachers and 1.9 million elementary teachers. Thirty-seven percent high school, $83^{\circ}$ \% middle school, and almost all elementary science teachers are teaching without degrees in science. These teachers "teaching out of their speciality area" often lack the means to improve their professional skills during their careers. Further, a recent study by Ingersoll (1999) revealed that in grades $7-12$, approximately $33^{\circ} \circ$ of the mathematics teachers and $20^{\circ}$ o of the science teachers do not have either a major or minor in their field. In "high poverty schools," this figure approacnes $50 \%$.

Ocean sciences are typically included in the American educational process only as a peripheral elective, if at all. Ocean science-as perceived by the educational hierarchy-is a relatively new discipline and is not part of the standard curriculum in most precollege or teacher training programs. State and national standards largely ignore ocean studies. Whether a cause or result of this situation, few graduates of ocean science degrees programs pursue careers in K-12 education. Based on a report by Nowell (2000), among graduates with bachelor degrees, less that $1^{\circ} \circ$ of those in the ocean sciences enter high schools as teachers, compared with $10 \%$ of the physics majors. Among those who do have degrees in science, few have studied the ocean sciences. If ocean sciences are to be incorporated into school curricula, the community of practicing oceanographers, who number approximately 3,400 (NSF/SRS, 1997), are a possible source of help. However, the ratio of oceanographers to students $(1: 15,294)$ suggests that one-to-one or one-to-few interactions between these scientists and students can have no hope of reaching more than a tiny fraction of students. The ocean sciences

' There are also scichtists identified with other discolines who wow in thr ocan sciones, but the ratio of scientists to students remans small. 
community has a crucial role to play in the national education reform process now underway. According to a 1990 NRC Report, Fulfilling the Promise: Biology Education in the Nation's Schools, sustained reform is best implemented by leadership from the scientific community "as both guide and goad, both resource and participant." The CORE Report (1996) concluded that agencies which fund ocean sciences research have "unequaled opportunities and untapped resources for precollege (K-12) education." This same study also challenged the ocean sciences research community and $\mathrm{K}-12$ educators to develop partnerships (both formal and informal) to, over the long term, mutually develop new ways to infuse the ocean sciences into K-12 education at all curricular levels.

These ocean science partnerships may help reverse students' lack of understanding and interest in entering science, and consequently their failure to pursue careers in science. It has been reported this disinterest in the sciences and failure to pursue ocean sciences careers by precollege and ultimately undergraduate and graduate students may be the result of several factors: uninspiring and/or poorly educated teachers, a lack of "hands-on" scientific experiences, disconnected and unattractive subject material, the perception that science is difficult and irrelevant, and changing societal patterns (Walker et. al., 1992). To improve ocean sciences education for all of our students, scientists' time, a limited and valuable resource, must be deployed in ways that magnify and multiply efforts. The National Oceanographic Partnership Program (NOPP) offers this capability through its support of partnering specifically designed to reach large numbers of teachers and students.

It was partially in response to these recommendations that funding for education programs was included in the first year of NOPP awards. NOPP was established by an act of Congress to foster the development of collaboratives which "share resources, intellectual talent, and facilities to strengthen science education and communication through improved knowledge of the ocean." The three education programs described in this manuscript, Project Oceanography, the BRIDGE, and COAST seek to meet the goal of a shared, coordinated national investment in ocean sciences education for the $\mathrm{K}-12$ and informal communities through involvement of scientists and well-prepared science professionals and educators. Combined, these efforts currently reach approximately $3,586,148$ students and 87,298 teachers (7,686 first and second tier teachers actually taught; 79,612 teachers reached through the authors' combined websites) each year nationwide (about six percent of all students and approximately four percent of the authors' teachers). The overarching goal of these three projects is to make quality ocean sciences content and activities, as well as the importance of research results, available to as many teachers and their respective precollege students within this country as possible.

The three NOPP education projects described in this article addressed the needs of educators, students and researchers, with the following intent:

- to increase accessibility and quality of materials and programs available for training pre- and inservice teachers and informal educators by enhancing content and integrating complementary instructional strategies;

- to improve hands-on and other interactive learning experiences, thereby enhancing the relevance of ocean sciences to teachers informal educators, students, and the general public;

- to bridge the information gap between research results and what the K-12 and informal science community know about the interpretations of those data;

- to build a multimedia delivery infrastructure to complement development, distribution, promotion, and subsequent implementation of curricular materials; and

- to obtain maximum benefit to the educational community from researchers' outreach activities.

\section{Approach}

An overview of each of the three NOPP educational projects in meeting these needs is described below:

\section{PROJECT OCEANOGRAPHY}

Project Oceanography is a live, satellite-televised science education program designed to enhance science and math learning in the middle school classroom. Ocean science researchers teach each program using a fully-equipped broadcast studio with advanced distance learning technologies, located on the St. Petersburg campus of the University of South Florida. The weekly half-hour programs are televised during the school day (11:30 ET). Two-way audio connectivity (a live telephone call-in) allows for interaction between the scientists in the studio and participants at remote sites. Interactivity is further enhanced by the presence of a live studio audience, composed primarily of school groups from up to 90 miles away. All programs and materials are distributed at no charge to participants. Teacher information packets and videos of past programs are also available on the Project Oceanography web site <http://www.marine.usf.edu/pjocean>. Although designed for use in middle school science 
classrooms, many of the instructional television (ITV) stations which televise the program rebroadcast it during after school and weekend hours, thereby making the program accessible to cable and satellite television viewers nationwide. The unlimited scale-up potential of this program makes it especially accessible to students in inner city and isolated rural areas.

Project Oceanography's major objective is to make a direct connection between ocean science researchers and students and their teachers in the classroom looking for a mechanism to participate in K-12 outreach activities. The project is mutually beneficial, providing the students with a real-world curriculum that is both current and accurate, science role models, and hands-on materials such as preserved fish and water-test kits, and the opportunity to experience the tools and techniques used in oceanographic research (Figure 1). Teachers receive free teaching materials prepared by experts, and unavailable in textbooks, which they can use for several years to enhance their lesson plans. Scientists benefit by having guidance and assistance in preparation of grade-appropriate materials, assurance their efforts will reach a large audience of both formal and informal science communities, and perhaps most importantly, the documentation of their efforts and products which is essential for tenure and promotion.

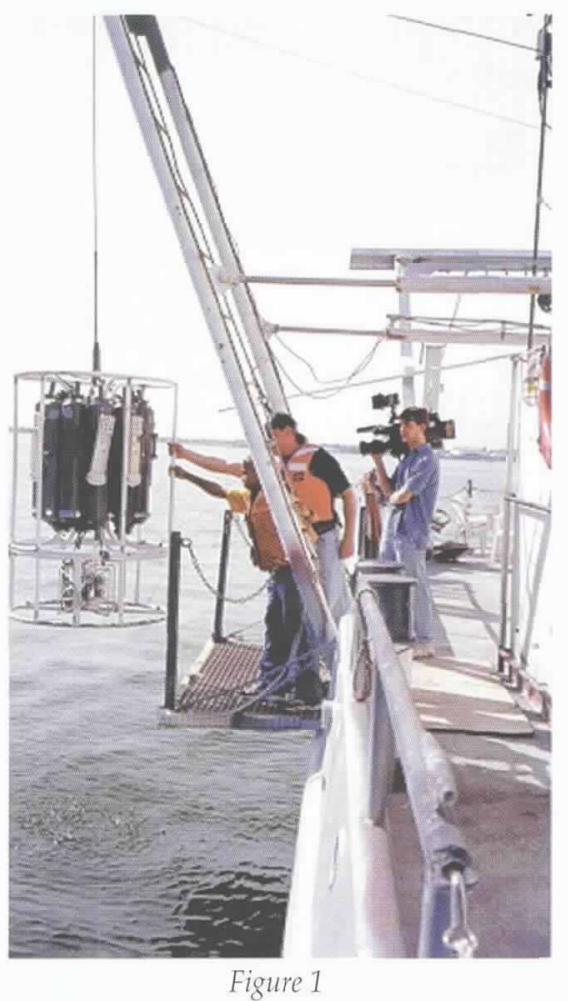

\section{Project Oceanography Products}

- 102 original half-hour programs on ocean science;

- 51 hours of videotaped programs;

- 24 University of South Florida scientists and 26 outside scientists have participated;
- 22 partnerships with state agencies, universities, private research laboratories, schools, and museums;

- International distribution network consisting of more than 302 registered sites in 35 states, the District of Columbia, Greece, Brazil, and England. This network includes 65 ITV stations that reach an estimated 1.7 million 6th, 7th, and 8th grade students in 3,500 schools; and

- Website for distribution of written curricular materials and on-demand distribution of past programs at <http://www.marine.usf.edu/pjocean>.

\section{THE BRIDGE: OCEAN SCIENCES EDUCATION TEACHER RESOURCE CENTER}

The BRIDGE: Ocean Sciences Education Teacher Resource Center <http://www.marine-ed.org > improves educators' access to data and current information about ocean sciences. Problems with teachers' access to current science-based teaching materials are acute in the ocean sciences, where the research community interacts infrequently with the educational community, and the few resources that are available reach only a small fraction of teachers and students nationwide. Without current, accurate information suitable for classroom use, science teachers cannot reasonably be expected to incorporate ocean sciences into their instructional programs.

The Web can address this situation. Internet access is commonplace in schools today but web access alone does not assure that teachers will locate useful and accurate information. A typical Web search results in hundreds of thousands of confusing page titles; busy teachers have little time to assess the quality and utility of thousands of sites.

The BRIDGE, sponsored by the National Marine Educators Association (NMEA) and the National Network of Sea Grant Marine Educators, is a focused portal site for ocean sciences education. It offers teachers an easy-to-navigate, comprehensive collection of the best on-line resources for ocean science education. Here, teachers can find materials prepared and approved by scientists and science educators, including:

- Oceanographic data and topical collections of marine science information suitable for use in classrooms;

- Bibliographies of on-line and traditional marine teaching materials and lesson plan collections;

- Information about grants and awards, careers, professional development and organizations, and ocean sciences research centers, aquariums, museums. science centers, field schools and graduate programs;

- Featured exemplary ("Stellar") sites; and

- Visitors' feedback and contribution forms and user evaluation forms.

The "Data Tip of the Month" series provides teachers with tips on incorporating online scientific data into 
classroom instruction in a manner that is easily understood by and interesting to students. This new section jumped quickly into the top-ten list of most-visited BRIDGE pages. "Data Tips" topics have included El Niño (1/99), Swordfish (2/99), Oil Spills (3/99), Exotics (4/99), Coral Bleaching (5/99), The Chesapeake Bay (6/99), Seafloor Mapping (7/99), Hurricanes (8/99), Sharks (9/99), The Gulf of Mexico Dead Zone (10/99), Aquaculture (11/99), Icebergs (12/99), and Whales $(1 / 00)$.

The Web makes partnering possible on a scale that would be unmanageable in any other medium. The BRIDGE network of links ties together resources from more than 900 sites containing ocean sciences material useful to teachers. Hundreds of science education resource websites have posted links to the BRIDGE, including CORE, the Environmental Protection Agency (EPA), the National Aeronautics and Space Administration (NASA), the U.S. Navy, National Oceanic and Atmospheric Administration (NOAA), the National Science Foundation (NSF), Sea Grant, the U.S. Department of Agriculture (USDA), the U.S. Geological Survey (USGS) and many universities, research institutions, and science education facilities. A network of regional coordinators conduct BRIDGE teacher training programs nationwide and work with local NMEA chapters to assure that regional information is available through the BRIDGE network.

\section{BRIDGE Products}

- BRIDGE visitors come from more than 90 countries;

- The BRIDGE network ties together 933 sites from academia $(33 \%)$, organizations $(24 \%)$, private industry $(14 \%)$, and government $(11 \%)$;

- Seventeen "Data Tips," new ones added monthly;

- 1,000,000 hits and 100,000 visitors annually; and

- "Scuttlebutt" ocean science education discussion list.

\section{THE CONSORTIUM OF \\ OCEANOGRAPHIC ACTIVITIES FOR STUDENTS AND TEACHERS (COAST)}

The Consortium of Oceanographic Activities for Students and Teachers (COAST) is an innovative collaborative designed to deliver technology enriched, oceanographic and coastal processes education to cadres of pre- and inservice K-12 teachers throughout the nation. The primary COAST partners include Pathfinder, a nationally recognized inservice and curriculum development program for K-8 teachers of predominantly minority students, Sea Scholars, a teachers-to-sea program with Web-based support, and STARBORD (Stimulating Teachers About Resources for Broad Oceanographic Research and Discovery), with expertise in visualization technologies and computational science tools for ocean sciences research. Each of these programs has individually created bridges between ongoing Naval, Sea Grant,

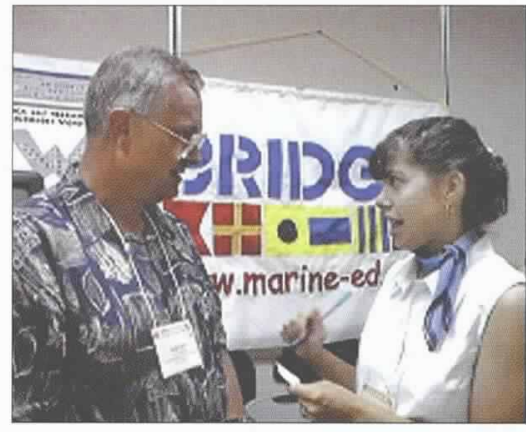

Figure 2

and university research and formal and informal learning environments through focused teacher education. The three primary COAST components and their respective institutions and locations are as listed: Pathfinder has been facilitated through The University of Southern Mississippi's Institute of Marine Sciences/JL Scott Marine Education Center and Aquarium, located in Biloxi; the Sea Scholars Program based at St. Norbert College in DePere, Wisconsin: and STARBORD, represented by Mississippi State University located in Starkville. Other essential partners in this collaborative include various components of the U.S. Navy, NMEA; and NOAA's National Sea Grant College Program and its various state programs. These COAST resources have been used to deliver integrated content and resources aimed at strengthening teachers in three areas: oceanographic and coastal processes science, content-oriented technology integration, and curriculum strategies to establish broad content integration, aligned with the National Science Education Standards (Figure 2).

During 1998 and 1999, the COAST: Pathfinder project involved 309 precollege pre-and inservice teachers in 12 different, 14-day Regional Institutes. The Regions represented included all coastal and Great Lakes states, as

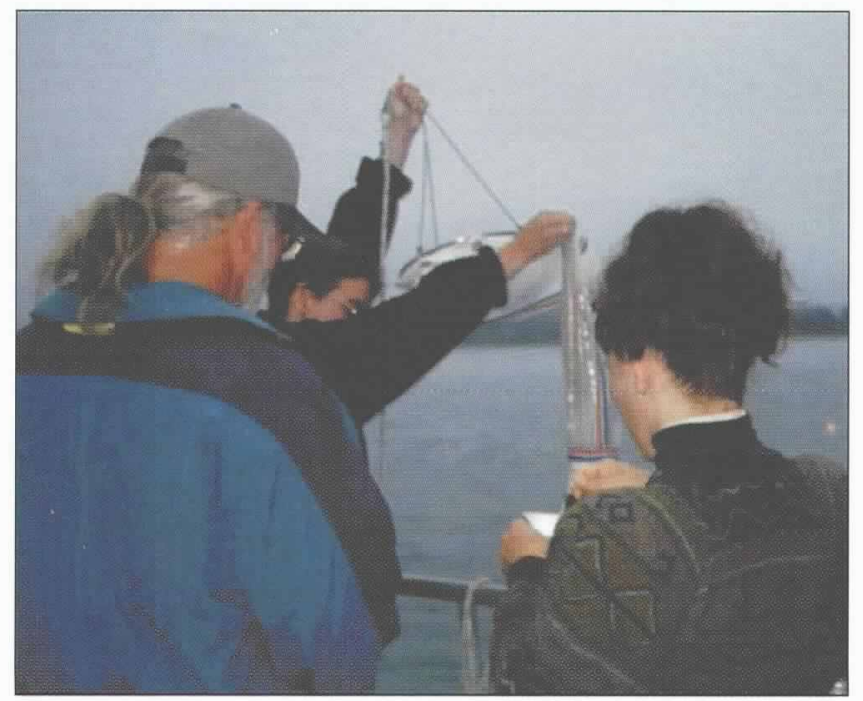

Figure 3 
well as Puerto Rico and the Pacific Islands. The geographic representation encompassed the Gulf and South Atlantic, the Mid-Atlantic, the Northeast, the Great Lakes, the Pacific, and the Pacific Island Network. The teacher participants were "immersed" in enhanced content knowledge involving: marine and aquatic resources, deep sea technologies, marine and aquatic pollution, physical parameters, and plate tectonics (Figure 3). The participants were also provided an augmented understanding of pedagogy, improved teaching methodologies, an appreciation of and understanding for the National Science Education Standards, gratitude for integrated curricular discussions, and a broadened knowledge of interactive, computational science based on the analyses and interpretations of scientific data sets derived from NOAA and the U.S. Navy (unclassified). Annually, each region averaged ten guest presenters with scientific and/or educational expertise in the six topics previously discussed. Regional field trips and "state of the art" technology sessions were given enviable evaluations by all participants.

Two essential requirements for participant selection for the Regional Institutes included forming cooperative learning groups to design professional development programs for implementation in their respective school districts and making presentations at local, state, regional or national meetings concerning either content or teaching strategies (Figure 4). Additionally, the teachers-to-sea effort involved placing teachers aboard oceanographic survey ships during the spring, summer, and fall of 1998 and 1999 for the total involvement of 56 precollege teachers, the majority of whom were involved in the Regional Institutes (Figure 5).

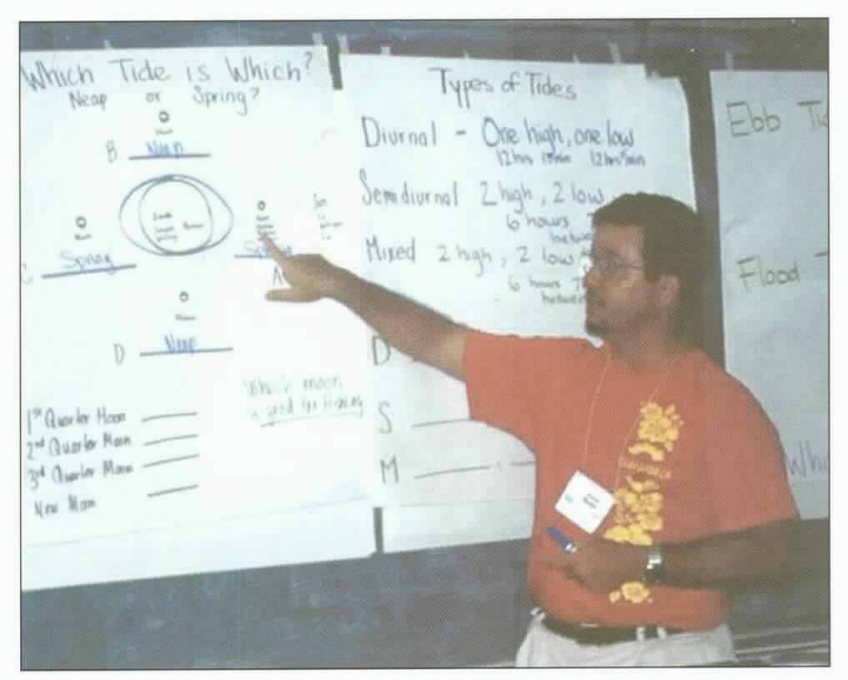

Figure 4:

It should be noted the COAST foundation has been based on the Operation Pathfinder teacher enhancement model implemented from 1993-1997 in which approximately 400 precollege teachers were involved in similar
Institutes, to include the development and field-testing of the Oceanography and Coastal Processes Resource Guide. The first edition of this Resource Guide was printed in late spring of 1998. The second printing of this Resource Guide occurred in June 1999 with its alignment to the NSES. This Resource Guide has also been pressed on CD after the incorporation of various appropriate glossaries, career exploration data, over 700 complementary resource URLs, and interactive data sets. Further, this Resource Guide was placed on the COAST Website at <http://www.coast-nopp.org/toc.html> in June 1999. This website received an average of more than 106,000 page requests in February 2000 and an average of 4,000 pages were printed daily during this time period.

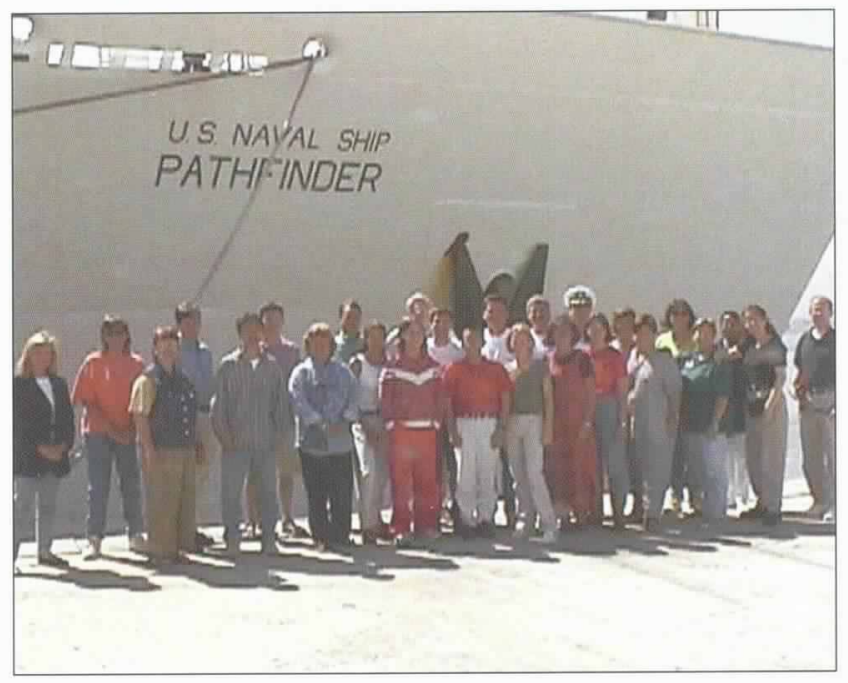

Figure 5

\section{COAST Products}

- 366 precollege teacher participants (Operation Pathfinder and Sea Scholars);

- 7,320 "second tier" teachers have been positively affected through the staff development programs implemented by the Regional Institute and Sea Scholar participants. These 7,320 teachers have the potential-over a five-year teaching career-of impacting 3,985,740 precollege students;

- Oceanography and Coastal Processes Resource Guidealigned with the NSES - developed by teachers for teachers in hard copy, CD-ROM, and on the COAST website;

- "Win-win" partnerships involving 22 sponsors from academia, state and federal government, businesses and industry, and the private sector;

- COAST website URLs include Pathfinder at <www.aquarium.usm.edu/coast01.htm> Sea Scholars at <http://voyager.snc.edu> and STARBORD at <www.coast-nopp.org/coast_partners/ starbord/index.html>;

- An average of 518,000 hits and 106,000 page 
requests for the Resource Guide-via its websiteare made monthly;

- 46 presentations at local, regional, national, and/or international meetings/conferences have been made since the inception of COAST;

- Over 700 related URLs, seven glossaries, career exploration data, and visualization tools for teachers have been added to the Resource Guide website; and

- Evaluation and assessment revealing significant differences in pre- and posttest cognitive achievement scores by all participants in all regions, and Likert-scale attitudinal achievement revealing that all participants perceived content, presenters, activities, and field-trips between $79^{\circ} \%$ to $97^{\circ} \%$ Very Valuable and/or Valuable and between 3\%, to $21^{\prime \prime \prime}$ Average and/or Limited Value.

\section{Challenges}

After nearly two and one-half years, these programs are beginning to have a positive and significant impact. Other proactive indications that the ocean sciences community is participating in science education reform include: 1) special education sessions at meetings of professional societies once devoted solely to communication of research results, 2) appearance of articles on education and outreach programs in publications of these professional societies, 3) proliferation of K-12 ocean science educational programs, materials and activities funded by federal agencies; and 4) the fact that many prestigious funding agencies are requiring research proposals to include an education or "impact on human resources" component.

Many additional efforts need to be coordinated and implemented to ensure the process of science and math education reform is successful. One major problem is sustainability of funding for effective programs. Ocean sciences education is currently supported by a myriad of unrelated grant programs, few of which are based on a national perspective. This situation almost assures sporadic, uncoordinated efforts. NOPP-by focusing its attention and funds on activities that nurture long-term research/education partnering on a national scale-contributes to an environment that can initiate and sustain positive change over the long-term. Such partnering enables the ocean sciences education community to merge isolated, ind ividual efforts into comprehensive, cooperative programs. However, coordinated and comprehensive evaluation and assessment are also necessary to illuminate what works and why, identify short and long-term outcomes, and examine both the content and process of projects as they relate to other ongoing activities and to national priorities.

Ocean sciences need to be incorporated into state and national science standards, which-as previously stated-largely ignore this major earth system (NRC, 1996). The study of the ocean is an inherently interdisciplinary science, aligned with the move toward adoption of both "integrative" and "Science, Technology, and Society" curricula. Although study of the ocean sciences offers exceptional opportunities to achieve the goals of national and state standards programs, the wording of the standards can lead to the conclusion, rightly or wrongly, that ocean sciences are not an important part of the material mandated by standards. Ocean educators need to consider standards in developing content and help teachers to use ocean sciences to meet standards, as well as long-term assessment and evaluation.

Perhaps the most effective method for advancing the ocean sciences curriculum in the classroom is for scientists to involve themselves in the $\mathrm{K}-12$ process, with teachers and with curricular materials. The 1996 NRC Report, The Role of Scientists in the Professional Decelopment of Scicnce Teachers, provides an excellent starting point for researchers and administrators who want to participate. After a period of self-education and/or working with science educators, scientists can play a vital role in sharing their knowledge of ocean sciences to improve existing curricula or develop/revise new materials to fill voids or provide greater "depth" in curricular contact. Scientists can also get directly involved with teachers by sharing their understanding of the scientific process, by providing research opportunities, and by mentoring. This involvement by science researchers with teachers and schools greatly enhances researchers' prestige within the community, i.e., with parents and students, and can help the scientists increase their chances of obtaining external funds. Teachers are also energized and more optimistic about the interpretations of scientific data and the importance of the results when they have improved access to equipment, journals, and scientific expertisethrough partnerships with scientists.

Just as scientists can convey enhanced respectability for K-12 teachers, so administrators and program managers can convey respect and support for scientists within their research communities. Administrators can assist by encouraging participation in education and outreach activities, revising rewards for these activities (e.g., from service to teaching activity), and building new collaborative partnerships with local schools and national educator organizations, e.g., NSTA and NMEA. Directors/Chairs of marine science departments should foster interaction between the ocean sciences and education faculties at the university level to incorporate content into teacher degree programs and educate graduates of ocean sciences degree programs regarding $\mathrm{K}-12$ teaching as a career option and the role 
that scientists can and should play in precollege education. This interaction will ensure that teachers have enhanced training and education in science, mathematics, and technological content, as well as integrative, hands-on learning strategies for the classroom.

The goal of sustainability and replication of successful programs requires more than current levels of federal funding will permit. Federal program managers can play a special role in the process by working to leverage funds from large foundations and corporations, taking active roles in publicizing and assuring nationwide distribution of results and products from these programs. These managers can also act as liaisons between the research and education communities to maximize productive collaborations by evaluating existing studies and continuing and planning additional/new studies where and when they are needed. As with most problems facing us today, there are no singular, simplistic solutions for ocean science education. Only carefully considered, multiple approaches will lead to incremental improvements for the new millennium and beyond.

\section{Recommendations}

Although ocean science information may be packaged and disseminated by others, the ocean sciences academic and research community is the source of content. Wide-scale functional connections and efficient communications between ocean scientists and educators are essential to improving ocean sciences literacy. NOPP's partnering orientation makes it an ideal catalyst. In The Role of Scientists in the Professional Development of Science Teachers (1996), The National Research Council recommends a number of excellent strategies for developing these linkages. Several of their recommendations suggest actions that NOPP and similar funding agencies should implement:

- Long term funding or renewability of funding. Most funding sources abandon projects after a few years, regardless of quality and achievement, and invest in new projects, in search of innovation. Innovation is important, but it can be nurtured cost-effectively within the context of established infrastructure. In a stable funding environment, educators and scientists can apply their time and skills to science education rather than producing endless streams of "new" ideas, configured to various funding agencies' specifications. NOPP and other funding sources should support the growth and evolution of successful programs over time.

- Fund professional third party eialuations over sufficient periods of time. Presently, we cannot be sure what impacts on student and teachers our programs will have over time. Evaluations that reveal what works and what doesn't work are expensive, but there are currently no better known mechanisms we can use to answer these questions.

- Fund scientists' educational activities with add-on grants but only when the proposed activities promise to make significant contributions to science education. Because there are so few ocean scientists and such a great need, it is important that researchers' expertise be directed toward maximum impact. It is often more desirable for researchers to collaborate with existing programs than to create many new, smallscale efforts. When new programs are created by researchers, they should be expected to be of high pedagogical quality and work in synergy with existing efforts.

\section{Vision for the Future}

The projects that NOPP has funded are ambitious, bringing together for the first time in a coordinated partnership the country's leading marine education programs and ocean sciences research communities. These projects have all leveraged investments in technology and national networking to deliver relevant current research and ocean science expertise to teachers and classrooms nationwide. Hundreds of educators and scientists representing many research and educational institutions are working together to administer these projects; hundreds of thousands of students and their teachers will benefit if these projects continue. The increased credibility for crossover activities, enhanced mutual respect and improved communications between scientists and educators have resulted in a "win-win" partnership for both groups and this country's precollege teachers, students, and the general public. Additionally, all of these programs are building new and effective partnerships among academia, government, industry, and the private sector.

The advent of expanded electronic communication technologies has already begun to revolutionize the way educational materials are delivered to students at all stages of their education. It is also bringing change to the fundamental nature of curricular and learning strategies. Several efforts are currently underway to develop multimedia distance learning programs, which integrate video, realtime data streams, and archived data to provide virtual "hands-on" learning experiences delivered directly to users via high speed Internet. One of these efforts, jointly funded by NSF and NASA, is the Digital Library for Earth Science Education (DLESE) in an initiative to establish a national digital library of earth science education curricula, associated archived data sets, and tools for handling real-time data <http://www.dlese.org>. The challenge for all of us is to continue the evolution of new applications of technology to meet the educational needs of the future citizens of the world.

\footnotetext{
"We must continue the critical dialogue that has begun and build together across party, regional, economic and other interests a comprehensive oceans agenda for the 21st century... We have to make this an American issue
} 
that transcends party and other philosophical differences, that is at the core of our own humanity and our obligation to our children and our grandchildren."

-President William Jefferson Clinton (1999).

\section{Acknowledgments}

The authors of this manuscript wish to express appreciation to the National Oceanographic Partnership Program, the Office of Naval Research, and the Consortium for Oceanographic Research and Education. Further, the authors are also grateful to the many partnerships-formed before and during- the implementation of these nationally recognized efforts.

\section{REFERENCES}

Consortium for Oceanographic Research and Education (CORE), 1996: Ocenns 2000: Bridging the MillennitaPartnerships for Stakeholders in the Oceans. A Report on the Interagency Partnership Initiative.

Ingersoll, R.M., 1999: The Problem of Underqualified Teachers in America's Secondary Schools. Educational Researcher, 28 (2), 26-37.

National Research Council, 1990: Fulfilling the Promise: Biology Education in the Nation's Schools. National Academy Press, Washington, D.C.

National Research Council, 1996: The Role of Scicntists in the Professional Development of Science Teachers. National Academy Press, Washington, D.C.

National Research Council, 1996: National Science Education Standards. National Academy Press, Washington, D.C.
National Science Foundation/SRS, 1997: SESTAT Integrated Data System. National Academy Press, Washington, D.C.

National Science Foundation Survey Report, 1988: International Survey Gives U.S. a Failing Grade in Science Education. pp. 1-4.

National Science Teachers Association, 2000: Science Education Statistics. Available: http://www.nsta.org/ pressrel/factsheet.asp

National Science Teachers Association, 1996: NSTA Reports-Third International Mathematios and Science Study.

Nowell, A., 2000: Education in Oceanography: History, Purpose, and Prognosis, pp. 195-200. In: 50 years of Ocean Discovery: National Science Foundation 19502000. National Academy Press, Washington, D.C.

U.S. Department of Commerce, National Oceanic and Atmospheric Administration, 1999: Tuming to the Sea: Amcrica's Ocean Future. Office of Public and Constituent Affairs, Washington, D.C., 64 p.

U.S. National Commission on Excellence, 1983: Nation at Risk: The Imperative Education Reform.

U.S. National Science Board, Commission of Pre-college Education in Mathematics, Science and Technology, 1983: Educating Americans for the 21st Century. National Science Foundation, Washington, D.C.

Walker, S.H., J.I. Jones, R.J. Shephard, M.J. Pelzcar, V. Osis, and L. Skupien, 1992: Shaping the Future-Sea Grant, Science and Society: The Role of Marine Education. Printed by NOAA-the Mississippi-Alabama Sea Grant Consortium, pp.1-21.

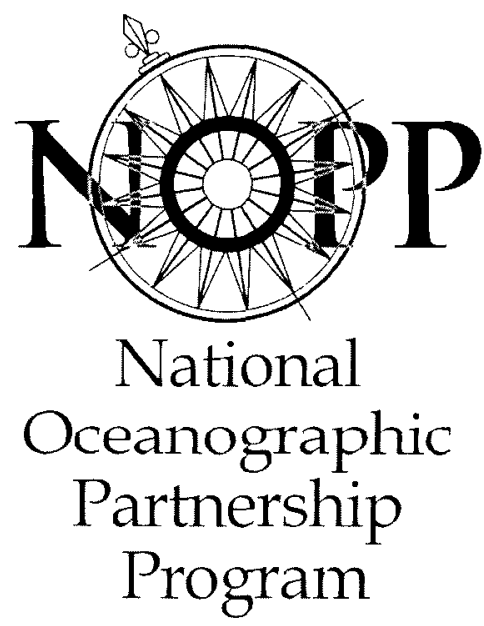

